\title{
HACIA LOS PRECEDENTES EN CHILE: REFORMA PROCESAL CIVIL Y FUENTES DEL DERECHO
}

\author{
TOWARD PRECEDENTS IN CHILE: \\ CIVIL PROCEDURE REFORM AND SOURCES OF LAW
}

Pablo Bravo-Hurtado*

\begin{abstract}
RESUMEN: Según las reglas del código civil la jurisprudencia no es fuente del Derecho en Chile. Sin embargo, diversas reformas procesales -en materia penal, laboral y a futuro civil- restringen el recurso ante la Corte Suprema a resolver solo aquellos casos de jurisprudencia contradictoria. ¿Este tipo de cambios procesales significan que Chile pasará a tener un sistema de precedentes vinculantes similar al common law? Este artículo estudia cómo los precedentes afectan, en mayor o menor grado, las prácticas interpretativas en distintos países. Y, a partir de esa perspectiva comparada, analiza en qué situación se encuentra Chile actualmente y en cuál terminaría de seguir con este tipo de reformas procesales. Se concluye que es necesario el reemplazo de la teoría binaria tradicional sobre fuentes del Derecho por otra que admita en grados y escalas, como la propuesta de MacCormick y Summers.
\end{abstract}

Palabras clave: Precedente vinculante, Reforma procesal civil, Fuentes del Derecho.

ABSTRACT: According to the rules of the civil code, case-law is not a source of Law in Chile. However, different procedural reforms -in criminal, labor and civil matters in the future- restricts the recourse before the Supreme Court to solve only those cases of contradictory case-law. Does this kind of procedural changes mean that Chile would pass through a system of binding precedents like the common law? This article studies how precedents affects, in a great or less degree, the interpretative practice in different countries. On that comparative perspective, analyzes in which situation is Chile nowadays and in witch will be if it follows this kind of procedural reforms. It concludes that is necessary the replacement of the traditional binary theory about sources of Law, for another that allows degrees and scales, like the MacCormick \& Summers's proposal.

Key words: Binding Precedents, Civil Procedure Reform, Sources of Law.

\section{INTRODUCCIÓN}

En 1992 Richard Cappalli -profesor de la Universidad de Temple, Filadelfia- dijo en esta misma revista: "Chile es un peladero de precedentes" ${ }^{1}$. Esa fue una de las conclusiones de su estadía de investigación enfocada a contrastar el procedimiento civil chileno con el estadounidense. Sin embargo, diversas reformas a la Corte Suprema han ocurrido desde entonces y ya es hora de revisar si la imagen que él se formó de nuestro país sigue estando

\footnotetext{
* Profesor de Derecho Procesal. Universidad Católica de Temuco, Chile. Abogado, Universidad de Chile (pbravohurtado@uct.cl).

1 Cappalli (1992) p. 208.
} 
vigente o no. Han pasado 20 años desde del artículo de Cappalli y, al parecer, Chile ha dejado de ser un terreno tan despoblado de precedentes como lo era a comienzos de los noventa.

En consecuencia, este artículo trata acerca de un tópico de interpretación jurídica, concretamente, el rol de la jurisprudencia como fuente del derecho. El aspecto de este tópico que interesa analizar aquí es cómo los cambios procesales a los recursos ante la Corte Suprema afectan el rol de la jurisprudencia en la interpretación.

Para abordar esta cuestión se estudiará el caso de Chile. Si bien se observarán los modelos de interpretación de la jurisprudencia que exhibe el derecho comparado, el objetivo final de este artículo es comprender a cuál de esos modelos adhiere actualmente nuestro país, por una parte, y a cuál se encaminaría de seguir las reformas al recurso ante la Corte Suprema en materias civiles, por la otra.

Este es un tópico recurrente en las ciencias jurídicas. La importancia, al menos fáctica-señala Alexy- que tienen los precedentes también en el Derecho europeo-continental es hoy subrayada desde todos lados. Lo que se discute es su valoración teórica. La discusión se centra ante todo en la cuestión de si se les puede atribuir el carácter de fuente del Dere$\mathrm{cho}^{2}$, sin siquiera detenernos primero en si acaso estamos entendiendo lo mismo por 'precedentes' en una u otra cultura ${ }^{3}$.

Ahora bien, replanteárselo una vez más, ahora en Chile, es especialmente oportuno hoy en día. En marzo del 2012 se presentó al Congreso un proyecto de ley de nuevo código procesal civil. El proyecto, además de oralizar los procedimientos de primera instancia, propone eliminar la tradicional casación de ley. A cambio, se instauraría un tipo nuevo de recurso ante la Corte Suprema que está orientado a solo unificar la jurisprudencia en casos específicos.

Esta reforma a la casación ha despertado una crítica severa: que a propósito de una reforma procesal se estaría alterando el sistema chileno de fuentes del Derecho. ¿Con estos nuevos recursos de unificación la jurisprudencia comenzará a ser fuente formal en Chile? Mas lo que corresponde a nuestra tradición jurídica es que la jurisprudencia no sea fuente del Derecho. Estas reformas procesales estarían, de paso, trastocando nuestra tradición ${ }^{4}$. Aquí se dialogará con esas críticas y se buscará desanudar el dilema.

\footnotetext{
2 Alexy (2007) pp. 261-262

3 'When the role of precedents is discussed comparatively, the question of whether they are formally binding or not comes up so quickly that one loses sight of varying conceptions of what "precednt" menas. AngloAmerican and Continental legal cultures probably differ more in how the conceive of "precedents" than in the actual binding forcé of prior adjudication” DAMAšKa (1986) p. 33 nota al pie 28.

4 'En primer término, se trata de una reforma que altera las bases que permiten comprender la actuación del máximo tribunal del país, afectando el sistema de fuentes del derecho privado. Esto queda especialmente reflejado tratándose de las facultades de la Corte Suprema, materia en la cual el proyecto elimina el actual recurso de casación en el fondo, estableciendo en su lugar el recurso extraordinario. La regulación revista para este nuevo recurso presenta importantes repercusiones en el sistema de derecho civil, por cuanto de sus disposiciones parece deducirse que el precedente de la Corte Suprema tendrá el carácter de vinculante y general, cuestión que atenta contra la regla asentada en nuestro derecho, establecida en el artículo $3^{\circ}$ del Código Civil, que dispone los efectos de las sentencias judiciales solo serán vinculantes para el caso particular’ AA.VV. (2012 pp. 1-2).
} 
Este artículo estará estructurado en cuatro partes. La primera (I) se enfoca en la teoría de fuentes del Derecho, en su origen histórico, su función y acerca del papel que se le asigna a la jurisprudencia dentro de nuestra tradición jurídica. En la segunda parte (II) se observa el derecho comparado para comprender cómo se interpreta la jurisprudencia en otros países, identificando los distintos grados de importancia que se le asigna. En la tercera parte (III) se estudia la reforma chilena a la Corte Suprema en materia civil y en la cuarta (IV) se analizará cómo afecta al sistema de fuentes del Derecho y hacia qué modelo de interpretación de jurisprudencia nos dirige.

\section{JURISPRUDENCIA Y FUENTES DEL DERECHO EN EL CIVIL LAW}

En este primer apartado abordaremos la importancia de las fuentes del Derecho y de la jurisprudencia dentro de la tradición jurídica del civil law $w^{5}$ Para ello es necesario entender primero qué es una tradición jurídica, qué papel juega en el funcionamiento de un sistema jurídico, a qué tradición pertenece Chile y cuál es el rol de las fuentes con la jurisprudencia dentro de la tradición a la que pertenecemos. En el apartado siguiente se verá cómo en otras tradiciones la jurisprudencia tiene un rol distinto y por qué.

Visto en términos simples, un sistema jurídico -como el chileno- es un conjunto operativo de reglas, órganos y procedimientos ${ }^{6}$. Sin embargo, tras cada sistema jurídico existe una tradición que lo sustenta. En los países, además de esas reglas, órganos y procedimientos, hay también un conjunto de puntos de vistas culturales que le dan sentido. Una tradición es la cultura tras el sistema. Merryman las define como un 'conjunto de actitudes profundamente enraizadas, e históricamente condicionadas, sobre la naturaleza del derecho, sobre el rol del derecho en la sociedad y en la política, sobre la adecuada organización y funcionamiento del sistema jurídico y sobre el modo en que el derecho debe ser creado, aplicado, estudiado, perfeccionado y enseñado'7. La definición de Merryman nos sirve para comprender que las tradiciones no son las que, en rigor, definen qué reglas, órganos y procedimientos tenemos; sino que son las que determinan cuáles son las opiniones compartidas sobre por qué y para qué se tienen.

Entonces, sigue el análisis, a pesar de las diferencias abigarradas entre los sistemas jurídicos de cada país, es posible agruparlos según sus tradiciones ${ }^{8}$. Es ya clásica -pero no por eso menos cuestionada ${ }^{9}$ la división del derecho del mundo occidental en dos. Por una parte se encuentra la tradición jurídica del common law, integrada principalmente por los países anglófonos que fueron colonias del imperio inglés (Gran Bretaña, Estados Unidos, Canadá, Australia, Hong Kong, etc. ${ }^{10}$. Por la otra se encuentra la tradición jurídica del

\footnotetext{
5 Para referir a la misma tradición jurídica también se utiliza la expresión 'romano-canónica' o 'europeo-continental'. Aquí se ha optado por 'civil law' porque, a pesar de no ser en español, mantiene mejor la simetría con 'common law'.

6 Merryman y Pérez-Perdomo (1997) p. 2.

7 Merryman y Pérez-Perdomo (2007) p. 2.

8 Para una división en 'familias' en vez de tradiciones, véase Zweigert y Kötz (1998) pp. 63 y ss.

9 Chase y Walker (2010) 666 pp.

10 Glendon et al. (2008) pp. 153 y ss.
} 
civil law (o 'romano-canónica') integrada por los países de Europa continental y las que fueron sus colonias respectivas (Francia, Alemania, Italia, Portugal con Brasil, España con Latinoamérica y Chile, etc. ${ }^{11}$. Ambas tradiciones se diferencian en distintos aspectos, pero si hay una cuestión que llama la atención sobre el resto es el distinto rol que cumplen las decisiones judiciales anteriores en las decisiones actuales.

En el common law se presta mucha atención a las decisiones anteriores. Sus jueces citan explícitamente fallos previos para decidir; la interpretación del Derecho discurre en elucidar cuál fue el sentido de la norma según cómo fue considerada en otros casos; y la enseñanza del derecho en las Universidades se enfoca en comprender cuáles son los fallos clave en la regulación de cada área ${ }^{12}$.

En la tradición del civil law no solo no es así, sino que llega a parecer opuesto. Los jueces no citan casos anteriores cuando deciden; la interpretación del Derecho es, sobre todo, el análisis de textos dictados por el Parlamento. Y la enseñanza del Derecho se enfoca en adiestrar a los alumnos en el manejo de los códigos que sistematizan esa legislación ${ }^{13}$.

En ambas tradiciones, para que se entienda bien, los juristas estudian los fallos de los jueces. Pero la diferencia no es solo de grado, no es que ellos les pongan más atención que nosotros. La diferencia es también de actitud. Cuando en el common law se estudia un fallo anterior es para encontrar en él la norma del Derecho. Mientras que en el civil law, un jurista usualmente utilizará un fallo como ejemplo para demostrar que los tribunales no se apegaron al criterio estrictamente legal.

Cabe preguntarse, entonces, por qué se dio esta diferencia. ¿Qué hizo que una y otra tradición desarrollaran actitudes tan distintas frente a la decisión de sus jueces? ¿En qué punto se separó tanto la historia del derecho en occidente para arribar a este resultado contradictorio? ¿Cuál es la explicación que se da dentro de una u otra tradición para dar cuenta de esta diferencia? El modo en el cual la tradición jurídica del civil law describe su propia diferencia con el common law es a partir de la teoría de fuentes. Lo que nos diferencia -se dice desde dentro de nuestra tradición- es que para nosotros la jurisprudencia no es fuente del Derecho, y para ellos sí lo es.

Pero ese es el modo, insisto, en que nosotros mismos describimos nuestra diferencia con ellos. Insisto en este punto para insinuar una pregunta: ¿en el common law se diferencian de nosotros de un modo simétrico? En otras palabras, cuando ellos describen la diferencia que los identifica por oposición a nosotros ¿dicen para sí '-aquí la jurisprudencia sí es fuente del Derecho y para el civil law no lo es'? La descripción que en el civil law se hace del common law (que allá la jurisprudencia sí es fuente) ¿es una descripción que ellos estarían dispuestos a adoptar como propia?

Curiosamente la respuesta es no. Pero no porque las decisiones judiciales para ellos no sean todo lo importantes que creemos que son. Esa descripción no la pueden adoptar como propia por una cuestión de premisas: el common law no desarrolló para sí una teoría

11 Glendon et al. (2008) pp. 17 y ss.

12 Glendon et al. (2008) pp. 276-284.

13 Glendon et al. (2008) pp. 132-136. 
de fuentes formales al modo del civil law ${ }^{14}$. Explicado de otro modo. Si a un abogado de common law se le formula la pregunta de si en su país la jurisprudencia es fuente formal del Derecho, él contestará que no. Pero contestará eso no porque la jurisprudencia tampoco sea fuente del Derecho para ellos al igual que para nosotros, sino porque ellos de partida no tienen una teoría de fuentes.

Esto es desconcertante. La teoría de fuentes es algo tan básico dentro de nuestra tradición que nos cuesta entender cómo en otros países se podría poner orden al Derecho sin un esquema de fuentes que las identifique, jerarquice, incluya o excluya unas u otras normas $^{15}$. La explicación es histórica.

La teoría de fuentes es, en realidad, un subproducto de la Revolución Francesa. El rol de los jueces en Francia o Inglaterra - la cuna de una u otra tradición- fue muy distinto durante el siglo XVIII. En Francia los jueces (Parlements) eran parte de una aristocracia 'de la toga' y actuaban como una fuerza conservadora. Aliados con el resto de la aristocracia francesa -sea nobiliaria o clerical- los jueces eran partidarios de mantener el ancien regime que la revolución buscaba derrocar ${ }^{16}$. En consecuencia, los revolucionarios franceses veían a los jueces como uno más de los enemigos que debían mantener a raya.

Para mantener neutralizados a estos jueces-enemigos la revolución francesa creó básicamente cuatro mecanismos. El primero fue la 'doctrina de separación de poderes' entendida como el aislamiento de la judicatura. La famosa frase de Montesquieu -que los jueces son la 'bouche de la loi- no debe ser entendida como una descripción sino como una orden. El énfasis estaba en que a los jueces les estaba prohibido intervenir en la labor de crear derecho (que le corresponde al Legislativo) y también les estaba prohibido intervenir en ejecutarla (que le corresponde al Ejecutivo). A los jueces solo les corresponde, de ahora en adelante, aplicar la ley para resolver conflictos individuales que se les plantean, nada más ${ }^{17}$.

El segundo mecanismo de neutralización fue, precisamente, la teoría de fuentes del Derecho. A partir de ahora, para saber qué ordena o prohíbe el Derecho sobre una materia será necesario acudir a determinadas 'fuentes' y no a lo que personalmente cree el juez. Esta teoría es creada para cumplir una particular función: identificar, jerarquizar y excluir a priori criterios de decisión ${ }^{18}$.

14 '[In the common law] there is no systematic, hierarchical theory of sources of law: legislation, of course, is law, but so are other things, including judicial decisions’ Merryman y Pérez-Perdomo (2007) p. 26.

15 'To the average judge, lawyer, or law student in France or Argentina, the traditional theory of sources of law represents the basic truth. It is a part of their ideology' Merryman y Pérez-Perdomo (2007) p. 25.

16 'Wielding extraordinary rule-making and other powers, the Parlements, composed largely of entrenched nobility of the robe, refused to register royal legislation intended to promote moderate reform and to salvage the monarchy.' LASSER (2004) p. 169.

17 'Montesquieu and others developed the theory that the only sure way of preventing abuses of this kind was first to separate the legislative and executive from the judicial power, and then to regulate the judiciary carefully to ensure that it restricted itself to applying the law made by the legislature and did not interfere with public official performing their administrative functions' Merryman y Pérez-Perdomo (2007) p. 17.

18 'The result of all this is that the accepted theory of sources of law in the civil law tradition recognizes only statutes, regulations, and custom as sources of law. This listing is exclusive. It is also arranged in descending order of authority.' Merryman y Pérez-Perdomo (2007) p. 24. 
A priori. La teoría de fuentes es un marco abstracto que constriñe de antemano. Los jueces ya no podrán ex post ponderar cuál criterio, de entre todos los disponibles, es la más justa para cada caso concreto, según su opinión. La teoría de fuentes cancela esa ponderación del juez y le entrega un cálculo anticipado.

Identificar. La teoría de fuentes postula, primero, que existen cinco posibles fuentes que es preferible mantener aisladas: la ley del parlamento, los reglamentos del ejecutivo, la costumbre, eventualmente la equidad y las decisiones judiciales anteriores (jurisprudencia). Cada fuente tiene sus propias características, su modo de interpretar, de ser creada, modificada o derogada.

Jerarquizar. El segundo postulado es que las fuentes tienen un orden de aplicación. La legislación es la fuente más importante y prevalece sobre el resto. La ley, se dice, 'es la fuente prístina, principal y primaria del Derecho' ${ }^{19}$. Después están los reglamentos, y en el evento de contradicción con la ley, cede el reglamento a favor de ella. Así sucesivamente con las demás fuentes en el orden que se presentaron.

Excluir. El tercer postulado es que no todas esas fuentes, en rigor, pueden crear Derecho. Solo algunas tienen esa aptitud y lo interesante es saber cuáles quedan excluidas. La costumbre sería una fuente que produce derecho solo cuando, según el país, la ley se remite a ella o en su silencio. La doctrina directa del corpus iuris civilis, o lo que los académicos decían de ella, perdió autoridad oficial pero continuó influenciando intelectualmente. Y la jurisprudencia -reza la teoría en su dogma más importante- no es fuente del Derecho en absoluto $^{20}$. Esto requiere mayor explicación.

Notemos que la teoría de fuentes fue formulada 'binariamente' - como un todo o nada, es o no es fuente- sin admitir grados intermedios. No se trata que, a partir de la Revolución, la jurisprudencia sería 'menos' fuente o tendría 'menor' peso relativo. No, la jurisprudencia dejó de constituir Derecho 'en absoluto'. Sin embargo, tanto hoy como en el siglo XVIII, es bastante obvio que, tal cual como se da en la práctica judicial, los fallos tiene algún grado de importancia. Mas la teoría de fuentes -así formulada binariamente por la Revolución- sería burdamente ciega frente a esos grados.

Cabe preguntarse, entonces, cómo logró perpetuarse en el tiempo esta teoría binaria de fuentes siendo que no daba cuenta de los matices que se dan en las prácticas interpretativas reales. La respuesta, en mi opinión, es que la teoría de fuentes del Derecho no buscaba ser descriptiva, sino normativa. Cuando la teoría dice que la jurisprudencia 'no es fuente' no está diciendo que no lo es, está diciendo que no lo debe ser. Con la teoría de fuentes no se buscaba describir neutralmente las prácticas interpretativas de los jueces tal cual son; se buscaba regularlas restrictivamente ${ }^{21}$.

19 Paillás (2008) p. 62.

20 'The most basic foundational idea of the French legal and political order has traditionally been the legislature, and the legislature alone, is supposed to have law-making power. Judges must not, and in some important sense cannot, usurp this legislative lawmaking power, on which the legislative possess the monopoly. [...] Law is composed of norm that possess a special and binding status, a status traditionally reserved to the products of the legislative and refused a priori, by definition an on principle, to judicial decisions'. LASSER (2004) pp. 168-169.

21 "This canonical understanding of the sources "sources of law" may well constitute the conceptual lynchpin of the entire French civil legal system. It is the conceptual device that enables de French to maintain 
Así podemos ver que 'la jurisprudencia no es fuente del Derecho' es el dogma más importante de la teoría de fuentes porque, en realidad, hay un mensaje político. Tras este postulado teórico los revolucionarios franceses están lanzando una advertencia a los jueces aristócratas; están advirtiéndoles que lo que ellos decían y pensaban ya no contará más como Derecho. Al igual que 'la bouche...' era una orden de Montesquieu, que 'la jurisprudencia no es fuente’ buscaba ser una prohibición tajante.

Por eso la teoría de fuentes necesitaba formularse en términos estrictamente binarios. Los revolucionarios no podían conceder que la jurisprudencia tuviera varios grados, con una escala de grises, porque el mensaje político perdería fuerza. Si se instalaba que, a partir de la revolución, la jurisprudencia solo pasaría a tener 'menor' importancia -pero conservaría algún grado de importancia al fin y al cabo- entonces los jueces aristócratas utilizarían estratégicamente ese mismo grado de discrecionalidad para oponerse a la revolución. Para ahogar toda oposición, la teoría de fuentes debía ser formulada como un 'todo-o-nada' en donde la jurisprudencia (lo que dicen los jueces-enemigos de la revolución) es nada.

Retomando, después de la separación de poderes y la teoría de fuentes, el tercer mecanismo de neutralización fue la codificación. Claro, según la teoría de fuentes la primera prioridad la tiene la ley. Mas en aquella época la legislación era algo dispersa, abundante y caótica. Luego, aún dentro de las restricciones de la teoría de fuentes, al juez-enemigo le quedaba un margen de discreción importante eligiendo una de entre las tantas leyes, posiblemente contradictorias, que existían. Para reducir ese margen de discrecionalidad se optó por concentrar toda las leyes en un solo cuerpo, el código, y a partir de ahí dar por derogada la demás legislación anterior. En consecuencia, cuando la teoría de fuentes señala que la primera obligación del juez es aplicar 'la ley', se está pensando en que aplicar la ley es aplicar el código y no otras leyes del ancien regime.

Y el cuarto mecanismo fue la casación. No bastaba con un código único más el dogma que solo debía ser aplicada la ley de ese código. Era necesario además un órgano fiscalizador. Ahora bien, como la judicatura era vista como enemiga -y era precisamente a quien había que fiscalizar- no se podía simplemente asignar a otro grupo de jueces esa labor de fiscalización. La solución fue crear una Cour de Cassation que en realidad no es parte de la judicatura aristócrata sino que pertenece al parlamento revolucionario ${ }^{22}$.

Esta Cour necesitaba además ser grande porque, en cuanto ente fiscalizador, debía ser capaz de revisar potencialmente todas las decisiones que dictaran cada uno de los juecesenemigos. Pero como la Cassation no era parte de la judicatura, no le correspondía a ella ‘juzgar' el caso y decir cuál era la solución correcta (eso sería ‘juzgar’ y le corresponde a los

simultaneously -in good faith and in all sincerity - a series of propositions that, to the American eye, appear irreconcilable'. LASSER (2004) pp. 171-172.

22 Merryman y Pérez-Perdomo (2007) pp. 39 y siguientes. Le Chapelier, citado por Gény, decía: 'Cree el comité que la casación de las sentencias contrarias a la ley no es un derecho del Poder Ejecutivo, al cual corresponde solo el de castigar al juez, sino que debía atribuirse a un Tribunal de Casación que, situado entre los tribunales y la ley, quede encargado de la vigilancia completa de la ejecución. Este derecho de vigilancia debe conferirlo el cuerpo legislativo, porque a la facultad de dictar la ley sigue naturalmente la de vigilar su observancia; de tal suerte, que si esto fuera posible, lo verdaderamente ajustado a los principios sería que las sentencias contrarias a la ley se casasen por decreto.' GÉNY (1925) p. 61. 
jueces); su función era solamente anular la decisión en que el juez 'infringía' la ley y reenviar el caso a otro juez menos díscolo ${ }^{23}$.

Este análisis nos permite concluir que en nuestra tradición jurídica la separación de poderes, la teoría de fuentes del Derecho - con el dogma binario de que la jurisprudencia no lo es- la codificación y el tribunal de casación están estrechamente atados. Son todos subproductos de la revolución francesa, un conjunto de mecanismos que interactúan entre sí para neutralizar a un estamento de jueces que eran enemigos de la revolución. Ese es el origen, contexto y función de la teoría de fuentes formales del Derecho en la tradición del civil law.

Chile hereda orgullosamente esa tradición y, en consecuencia, también dispone de esos cuatro mecanismos de neutralización de los jueces. Tenemos el postulado de separación de poderes como aislación ${ }^{24}$, tenemos códigos sistematizados ${ }^{25}$, la Corte Suprema tradicionalmente ha ejercido la casación ${ }^{26}$ y también adherimos a la teoría de fuentes.

En efecto, los primeros artículos del código civil chileno se dedican a este tema. Es significativo que abre el código la definición misma de ley ${ }^{27}$. Nótese que el artículo uno en vez de usar una descripción más neutral -definiendo 'ley', por ejemplo, como normas escritas dictada por un parlamento o similar-Andrés Bello opta por resaltar que, antes que todo, es una 'declaración de la voluntad soberana'28. Este énfasis se entiende por el contexto revolucionario del siglo XVIII. Cuando la definición de ley afirma que a partir de ahora la soberanía estará del lado de la legislación, al mismo tiempo se está quitando la soberanía de otros lugares ${ }^{29}$.

De donde se está quitando es precisamente de los lugares que sustentaban el régimen aristocrático del ancien regime: la costumbre y la jurisprudencia. La costumbre queda subordinada a las remisiones explícitas de la ley en el artículo segundo ${ }^{30}$. Y la jurisprudencia, que es en la que nos enfocaremos, está regulada en el artículo tercero del siguiente modo:

\footnotetext{
23 Para más información, véase Atria (2004) pp. 253 y ss.

$24 \mathrm{CPol} / 1980$ - Art. 73: 'La facultad de conocer de las causas civiles y criminales, de resolverlas y de hacer ejecutar lo juzgado, pertenece exclusivamente a los tribunales establecidos por la ley. Ni el Presidente de la República ni el Congreso puede, en caso alguno, ejercer funciones judiciales, avocarse causas pendientes, revisar los fundamentos o contenidos de sus resoluciones o hacer revivir procesos fenecidos.'

25 Código Civil, de Procedimiento Civil, Penal, de Procedimiento Penal, del Proceso Penal, Comercial, Tributario, etc.

26 CPC/1903 - Art. 764-808.

27 CC/1856 - Art. 1: 'La ley es una declaración de la voluntad soberana que, manifestada en la forma prescrita por la Constitución, manda, prohibe o permite.'

28 'Both to bring about this kind of transformation and to consolidate the accomplishments of the [French] revolution, an ideology was needed, and nationalism -the ideology of the state- met this need. And if nationalism was the prevailing ideology, sovereignty was the basic premise of its legal expression' MerRYMAN y Pérez-Perdomo (2007) p. 20.

29 'Thus state positivism, as expressed in the dogma of the absolute external and internal sovereignty of state, led to a state monopoly of lawmaking [...] The legislative power is by definition the lawmaking power, and hence only the legislature could make law' Merryman y Pérez-Perdomo (2007) p. 23

30 CC/1856 - Art. 2: 'La costumbre no constituye derecho sino en los casos en que la ley se remite a ella.'
} 
[En Chile] solo toca al legislador explicar o interpretar la ley de un modo generalmente obligatorio. Las sentencias judiciales ${ }^{31}$ no tienen fuerza obligatoria sino respecto de las causas en que actualmente se pronunciaren ${ }^{32}$.

Como vemos, este artículo tiene dos partes que están relacionadas. La primera aclara que la interpretación (o explicación) de la ley corresponde exclusivamente al legislador. Puesto en el contexto del siglo XVIII, aquí el código se anticipa a que los jueces aristócratas traicionen la nueva legislación revolucionaria so pretexto de estarla explicando o interpretando.

La segunda parte dice respecto de la jurisprudencia algo que, en rigor, es distinto a lo que dijo respecto de la costumbre. No dice que las decisiones judiciales 'no constituye Derecho' (como dice con la costumbre) sino que dice que 'no tiene fuerza obligatoria'. Pero ambas expresiones -'no constituye Derecho' y 'no tiene fuerza obligatoria'- no pueden considerarse sinónimas sin más. Esto porque el término 'obligación' y sus derivados -como 'obligatorio(a)' del artículo tres- es utilizado varias veces en un sentido técnico en el resto del código ${ }^{33}$.

Ahora bien, si de obligaciones se trata, el artículo más importante es el que señala cuáles son sus fuentes. El artículo 1437 señala que las fuentes de las obligaciones (de donde 'nacen') son los actos unilaterales, los contratos, los cuasicontratos, los daños (delitos y cuasidelitos) y, por último, pueden nacer directamente de la ley ${ }^{34}$. Mas lo interesante es notar aquello que el artículo 1437 no dijo, enfocarnos en aquello que fue excluido como fuente.

Lo que no dice es la 'costumbre' ni la 'jurisprudencia'. Según el artículo 1437 ellas están excluidas como fuentes de obligaciones civiles. La costumbre está en algo mejor situación porque si bien el 1437 no la menciona, al menos el artículo dos la reconoce como fuente cuando la ley le presta apoyo explícito. Mientras que la jurisprudencia nunca generará obligaciones civiles por sí sola, el artículo 1437 la niega como fuente y el artículo tres ('no tendrá fuerza obligatoria') confirma esa negación ${ }^{35}$. De este modo el artículo tres del código civil chileno adhiere a la tradición de la teoría de fuentes y a su dogma más importante, que la jurisprudencia no es fuente.

31 La Comisión Revisora del 'Proyecto de 1853' cambió la expresión 'decisiones de los tribunales' por la actual 'sentencias judiciales', por iniciativa de Andrés Bello con la oposición de Gabriel Ocampo, Guzmán (2007) p. 23.

32 El "Primer Proyecto", el redactado personalmente por Andrés Bello antes de 1840 regulaba del siguiente modo la jurisprudencia: 'Artículo 9. Los jueces pueden interpretar las leyes en cuanto aplicables al caso especial sometido a su conocimiento; y les es permitido fundar su interpretación en decisiones judiciales anteriores, pronunciadas por una Corte Superior o Suprema, y pasadas en autoridad de cosa juzgada; pero se les prohíbe dictar en sus fallos disposiciones generales' GuZMÁN (2007) pp. 15-18.

33 CC/1856 - Art. 3, 7, 14, 407, 697, 1622, 2226, 2489, La expresión exacta del artículo tres 'fuerza obligatoria' es utilizada también en el artículo 553: 'Los estatutos de una corporación tienen fuerza obligatoria sobre toda ella, y sus miembros están obligados a obedecerlos bajo las penas que los mismos estatutos impongan'.

34 CC/1856 - Art. 1437: 'Las obligaciones nacen, ya del concurso real de las voluntades de dos o más personas, como los contratos o convenciones; ya de un hecho voluntario de la persona que se obliga, como en la aceptación de una herencia o legado y en todos los cuasicontratos; ya a consecuencia de un hecho que ha inferido injuria o daño a otra persona, como en los delitos y cuasidelitos; ya por disposición de la ley, como entre los padres y los hijos sujetos a patria potestad.

35 La fuerza obligatoria -finaliza el artículo tres CC/1856- la tendrán solamente 'respecto de las causas en que actualmente se pronunciaren'. Aquí el código se está preocupando de no pasar a llevar la acción de cosa juzgada por enfatizar tanto en la negación de la jurisprudencia como fuente. 


\section{PRECEDENTES EN EL DERECHO COMPARADO}

En el apartado anterior se analizó qué función cumple la teoría de fuentes del Derecho dentro de nuestra tradición del civil law, por una parte, y se ha propuesto una explicación de por qué la jurisprudencia es tajantemente excluida: junto a la separación de poderes, la codificación y la casación, fueron mecanismos diseñados para neutralizar a los jueces enemigos de la revolución francesa. Después se explicó cómo esa tradición de la teoría de fuentes -con el dogma de la negación de la jurisprudencia- fue finalmente acogida en Chile. En este segundo apartado, en cambio, se observará la evolución en otros países y cómo eso desembocó en actitudes más inclusivas respecto a las decisiones judiciales previas en las decisiones actuales.

En Inglaterra la historia fue totalmente distinta. Ahí los jueces no eran aristócratas conservadores, como en Francia, sino que eran una fuerza progresista que también estaba a favor de derrocar al feudalismo. Por eso los revolucionarios ingleses no veían en sus jueces a unos enemigos de la causa, sino como aliados poderosos ${ }^{36}$. En consecuencia, en vez de restringirlos, les daban un amplio margen de acción. Ellos terminaron confiando en sus jueces, nosotros no.

Este distinto rol de la judicatura en el siglo XVIII marcó el perfil de los jueces en la tradición jurídica del common law hasta hoy. Como sus jueces eran aliados -esto es lo históricamente importante- ellos no tuvieron la necesidad de desarrollar los cuatro mecanismos de neutralización como en Francia.

En primer lugar, esto explica la distinta comprensión que se dio de la separación de poderes (primer mecanismo). Mientras en el civil law la doctrina de la separación es vista como un aislamiento de la judicatura, en el common law lo ven de un modo casi opuesto, como pesos-y-contrapesos. En vez de abstenerse de intervenir en los otros poderes -que es la versión genuinamente francesa-, se entiende que el rol de los jueces es intervenirlos para controlarlos y, al mismo tiempo, ser intervenidos y controlados por ellos ${ }^{37}$.

Esto explica, segundo, por qué en el common law no se dio un fuerte movimiento codificador (tercer mecanismo). Si bien también tienen recopilaciones de reglas, ellas no cumplen el rol, ni tienen el protagonismo, que tienen dentro del civil law. Tampoco se le asigna importancia a la sistematización cerrada de las normas, propia de los códigos $^{38}$.

En tercer lugar, en el common law tampoco existe un símil de la Cassation (cuarto mecanismo). Ellos también tienen Cortes Supremas, por supuesto, mas ellas cumplen un rol totalmente distinto. La Cassation debía ser un único gran órgano fiscalizador-capaz de revisar muchos casos para mantener un control de cerca- ante el cual fuera fácil acceder con una denuncia sobre cualquier juez infractor de la ley revolucionaria. En el common law, en cambio, la Corte Suprema revisa muy pocos casos al año, no más de cien probablemen-

\footnotetext{
36 Merryman y Pérez-Perdomo (2007) p. 24.

37 Merryman y Pérez-Perdomo (2007) p. 17.

38 'On the Continent, where it was thought necessary to reject the jus commune, it was natural that the new legal systems were codified; in England, where it was thought necessary to retain the common law, no need for codification was felt' law' Merryman y Pérez-Perdomo (2007) p. 22.
} 
$\mathrm{te}^{39}$, y es muy difícil acceder a ella. Como los jueces no eran enemigos, no desarrollaron una casación porque no necesitan sobre sí un gran órgano fiscalizador intrusivo. De este modo, la Corte queda liberada para abocarse a resolver solo problemas puntuales de competencias entre Estados federados y de zanjar jurisprudencias contradictorias.

Y esto explica, por último, el dato que nos desconcertó en el primer apartado, que en el common law no se desarrolló, ni tiene acogida, la teoría de fuentes del Derecho (segundo mecanismo). Como los jueces eran aliados de la revolución, no era necesario jerarquizar ni excluir a priori sus criterios de decisión ni lanzarles un mensaje político restrictivo. Los revolucionarios ingleses confiaban en los criterios de sus jueces porque venían dictando fallos antifeudales y antimonárquicos desde hace mucho tiempo.

Sin una teoría de fuentes a la base del common law, tampoco se pudo dar su dogma más importante de que la jurisprudencia no es fuente. A la inversa, como los jueces eran aliados, sus fallos reflejaban bien las ideas antifeudales y antimonárquicas que también promovían los revolucionarios ingleses y, en consecuencia, le reconocían mucho valor a sus decisiones en la formación del nuevo Derecho ${ }^{40}$.

De este modo fue que en el common law se terminaron desarrollando idiosincrasias tan distintas acerca de las decisión de sus jueces. Sin una teoría binaria de fuentes en el common law, ellos tampoco ven la diferencia entre una y otra tradición binariamente-como sí la vemos nosotros- como si fuera una disyuntiva entre para quienes la jurisprudencia es o no es fuente del Derecho. Ellos dicen algo que, si ponemos atención, es distinto.

En el common law describen las diferencias entre las dos tradiciones en el uso de las decisiones judiciales previas del siguiente modo: -'nosotros tenemos precedentes y ellos no'. Pero, cabe aclarar desde ya, la idea de que en el common law 'tienen precedentes' no es sinónima a la idea de que para ellos 'la jurisprudencia sí es fuente del Derecho'. Viceversa, decir que nosotros 'no tenemos precedentes' no es sinónimo a decir que acá la jurisprudencia no es fuente del Derecho. Confundir ambas ideas omitiría un matiz interesante.

La verdadera diferencia, como la entienden ellos, es si acaso un único fallo anterior podría llegar a hacer cambiar o no, por sí solo, los criterios de decisión a futuro. Eso es precisamente lo que entienden por 'precedente', es decir, un único fallo previo que ha alcanzado una potencia tal de sentar pauta para los casos posteriores sobre cierta materia. En el civil law, como lo ven desde fuera, también se toman en cuenta las decisiones judiciales previas pero no cada una por sí sola. Solo se podrá cambiar el criterio de decisión a futuro si y solo si se acumula una suma de fallos suficientemente numerosa que replican el mismo nuevo criterio. Desde el common law dicen que en nuestra tradición 'no tenemos precedentes' porque no le reconocemos a nuestros fallos una potencia individual tal de cambiar tendencias. Ellos dicen que tenemos, en remplazo, un sistema de 'jurisprudencia constante', es decir, que solo cuando se reúnen varios fallos con el nuevo criterio entonces recién ahí reconocemos un cambio en la tendencia judicial ${ }^{41}$.

39 Wheeler (2004) p. 248. El año 2001 falló solo 88 casos.

40 Sobre el precedente en Inglaterra en español, véase Whittaker (2008) pp. 37-83.

41 Glendon et al. (2008) p. 133 y ss. 
No se trata, entonces, de que en una tradición las decisiones anteriores no importan y en la otra sí, en que en una son fuentes y en las otras no, como un todo o nada. En ambas tradiciones los fallos anteriores son tomados en cuenta pero en distinto grado. El derecho comparado exhibe un panorama variopinto que exige un marco teórico que rinda cuentas de esa variedad. Ese nuevo marco lo aporta el estudio comparado de Neil MacCormick y Robert Summers, llamado Interpreting Precedents de 1997, uno de los más ambiciosos en su tipo $^{42}$. La conclusión más importante de su estudio es la siguiente:

La primera gran similitud es que el precedente ahora juega una parte significativa en la toma de decisiones judiciales y en el desarrollo del Derecho en todos los países y tradiciones jurídicas que han sido revisadas [Alemania, España, Estados Unidos, Finlandia, Francia, Italia, Noruega, Polonia, Reino Unido, Suecia y en la Comunidad Europea]. Esto es así incluso si los precedentes son o no reconocidos oficialmente como formalmente vinculantes o solamente como teniendo otra fuerza normativa en cierto grado ${ }^{43}$.

La jurisprudencia -nos está diciendo MacCormick \& Summers- juega una rol significativo en los distintos países, sea o no sea reconocida formalmente como fuente. Aun si ese reconocimiento es tajantemente rechazado -como en la Cour de Cassation en Francia en donde la citación de fallos anteriores está prohibida ${ }^{44}$ - la jurisprudencia jugará de todas formas un rol importante a través de otros grados de fuerza normativa. Y para dar cuenta de esa diversidad de grados, MacCormick \& Summers desarrollaron una escala de cuatro niveles, de mayor a menor:

(10) Vinculación formal. Una sentencia que no respeta la obligatoriedad del precedente no está conforme a Derecho y, en consecuencia, está sujeta a revocación por un recurso procesal.

(a) Vinculación formal inmodificable (sin overrulling $)^{45}$.

(i) 'Vinculación estricta' - debe ser aplicado a todos los casos, sin excepción.

(ii) 'Vinculación derrotable' - debe ser aplicado en todos los casos a menos que sea aplicable una excepción (las excepciones pueden estar bien definidas o no)

(b)Vinculación formal (con o sin excepciones) que está sujeta a overrulling o modificación.

(2o) Sin vinculación formal pero tiene fuerza. Una sentencia que no respeta la fuerza de un precedente, aunque es conforme a Derecho, está sujeta a críticas sobre esta base, y puede estar sujeta a revocación sobre esta base también.

\footnotetext{
42 MacCormick y Summers (1997) 585 pp.

43 MacCormick y Summers (1997) pp. 531-532.

44 En extenso sobre Francia, véase Troper y Grzegorczyk (1997) pp. 103-140.

45 'Overruling' es la facultad que tiene la Corte Suprema en el common law de modificar una tendencia jurisprudencial en atención a que han cambiado los contextos históricos, sociales o culturales. BANKOWsKI et al. (1997) pp. 342-345; Marinoni (2010) pp. 388 y ss.
} 
(a) Fuerza derrotable -debe ser aplicado a menos que entren en juego excepciones (las excepciones pueden estar bien definidas o no)

(b) Fuerza compensable -debe ser aplicado a menos que sean aplicables razones contrarias.

(3o) Sin vinculación formal ni tiene fuerza (como se define en (2)) pero provee un apoyo adicional. Una sentencia que falta al precedente sigue estando conforme a Derecho y puede estar justificada, pero no tan bien justificada como si invocara un precedente, por ejemplo, para mostrar que la decisión tomada es armónica con el precedente.

(40) Un mero valor ilustrativo o de otro tipo ${ }^{46}$.

Después MacCormick \& Summers aplican esta escala para observar el derecho comparado. Bajo esta perspectiva, los países de common law están en el grado más alto ${ }^{47}$. Allá los precedentes establecidos por las Cortes Supremas son formalmente vinculantes para los tribunales inferiores $\left(1^{\circ}\right)$, incluyendo a las Cortes de Apelaciones. Cuando un tribunal inferior no sigue el precedente del superior, entonces su sentencia no está conforme a Derecho y será necesariamente revocada en el recurso procesal ${ }^{48}$.

Sin embargo, incluso en el common law no llega nunca a ser una 'vinculación estricta' (1ª.i.) porque los tribunales inferiores siempre conservan algún grado al menos de derrotabilidad ( $1^{\circ}$.a.ii) y las Cortes Supremas mismas también se reservan la posibilidad de modificar posteriormente (overulling) el precedente $\left(1^{\mathrm{o}} . \mathrm{b}\right)^{49}$.

Aplicando ahora la escala al civil law afirman MacCormick \& Summers 'la imagen caricaturesca de los sistemas de civil law como libres de los grilletes del precedente, en contraste con el common law esclavizado a su propio pasado (o "preservando el buen viejo orden"), ciertamente ya no es ni remotamente precisa, si alguna vez lo fue ${ }^{50}$. Entre las dos tradiciones no hay una marcada dicotomía -dicen los autores- sino un continuum.

En los sistemas de civil law -aunque los tribunales rara vez lo admitan, denuncian MacCormick \& Summers- en la práctica generalmente se reconoce que los precedentes al menos tienen una gran fuerza $\left(2^{\circ}\right)$ aunque derrotable $\left(2^{\circ} . a\right)$ o compensable $\left(2^{\circ} \cdot b\right)^{51}$. Además, en el civil law la jurisprudencia suele ser citada para proveer un apoyo adicional $\left(3^{\circ}\right)$ especialmente para aquellas decisiones que, por sí solas, parecieran sostenerse sobre una base jurídica demasiado endeble sino es por el precedente que las apoya ${ }^{52}$.

\footnotetext{
46 MacCormick (1997) pp. 554-555. El primero en utilizar esta escala en Chile fue Couso (2007) pp. 151-152.

47 'The conception of the force of precedent that now prevails in England is the most extreme on any to be found in the modern world.' Dawson (1987) p. 80.

48 MacCormick y Summers (1997) p. 532.

49 MacCormick y Summers (1997) p. 532 ; Bankowski et al. (1997) pp. 368-378.

50 MacCormick y Summers (1997) p. 532.

51 Existirían buenas razones para que en el civil law la jurisprudencia no alcance el nivel $\left(1^{\circ}\right)$ de la vinculación formal al modo del common law. '[A] doctrine of formally binding precedent would be far more rigid in Continental than in the common-law institutional framework. The primary reason is not so much the greater spirit of obeisane to superiors in the former than in the latter as the different understanding of precedent.' DAMAšKA (1986) p. 37 nota al pie 37.

52 MacCormick y Summers (1997) p. 532.
} 
Ahora bien, si usamos la escala de MacCormick \& Summers para describir a Chile hoy ¿en qué grado nos encontraríamos actualmente? Lo primero que notaríamos es que no estamos en el grado más alto. A diferencia del common law donde los precedentes sí tienen vinculación formal $\left(1^{\circ}\right)$-eso los sitúa en el grado más alto en la escala- en Chile está descartada esa vinculación. El artículo tres del código civil chileno, y la tradición tras ese artículo, niega de antemano el reconocimiento de la jurisprudencia como fuente formal del Derecho (supra II). Con el artículo tres vigente, ningún sentencia en Chile será, en estricto rigor, 'contraria a Derecho' por el solo hecho de contradecir cierta jurisprudencia.

Descartado el grado más alto, aún quedan otros tres grados inferiores. Cabe la posibilidad de que los fallos anteriores tengan una fuerza especial $\left(2^{\circ}\right)$, sirvan de apoyo adicional relevante $\left(3^{\circ}\right)$ o sean un mero dato ilustrativo $\left(4^{\circ}\right)$. ¿En cuál de esos otros escalones restantes se encuentra Chile? En mi opinión, especialmente si observamos las prácticas interpretativas en materia civil, sería exagerado afirmar que en Chile los fallos 'tienen una fuerza' especial $\left(2^{\circ}\right)$. A la inversa, está instalada la idea que la independencia judicial significa que el juez inferior es libre de tener su propio criterio jurídico, distinto al de los superiores, y que no es criticable por eso. En consecuencia, no se da el elemento del grado $\left(2^{\circ}\right)$ de que el fallo que se aparte del precedente 'esté sujeto a críticas sobre esa base'.

Entonces nos restarían solo los grados $\left(3^{\circ}\right)$ y $\left(4^{\circ}\right)$. Aquí sí pareciera encontrarse Chile, en algún punto intermedio entre ambas. En efecto, los fallos son usados por los tribunales como un apoyo adicional ( $\left.3^{\circ}\right)$. Al igual que en el resto del civil law, los jueces chilenos echan mano a fallos anteriores especialmente cuando sienten que la postura jurídica que buscan posicionar es endeble por sí sola. Así, encontrar un fallo de un tribunal superior que vaya en la misma línea sirve para legitimar una decisión que, sin otro antecedente, aparece jurídicamente débil.

Sin embargo, si la postura puede ser sólida solo en base a los estatutos legales involucrados, el juez no gastará tiempo en buscar fallos sobre el asunto. En esa situación de una base legal sólida, podría darse que el juez cite un fallo con un valor meramente ilustrativo $\left(4^{\circ}\right)$. Mas eso, si bien se puede dar en Chile, será visto como un lujo para jueces sobrecargados de $\operatorname{casos}^{53}$.

Por último, los autores advierten que este estudio comparativo repercute en la teoría general del Derecho. Particularmente, sirve para criticar las concepciones simplistas acerca de la validez jurídica -que intentan una distinción tajante entre válido e inválido- y contra la doctrina de fuentes del Derecho, que a su turno intenta una distinción fuerte entre lo que es fuente formal y no lo es ${ }^{54}$. La crítica que formulan MacCormick \& Summers en contra de esas concepciones es que -después de analizar los reportes sobre interpretación de la jurisprudencia de Alemania, España, Estados Unidos, Finlandia, Francia, Italia, Noruega, Polonia, Reino Unido, Suecia y en la Comunidad Europea- solo se puede concluir que:

\footnotetext{
53 La doctrina pareciera reconocer más el aporte en términos generales: 'Un panorama de la evolución del derecho privado nacional [chileno] no puede olvidar el rol de la jurisprudencia y la doctrina en la interpretación de las normas del Código Civil, en la elaboración de teorías generales ya de categorías que permitieron a este texto adaptarse a la evolución social'. TAPIA (2005) pp. 471.

54 MacCormick y Summers (1997) p. 542.
} 
Los precedentes no tienen una validez al modo todo-o-nada característico de los actos realizados bajo los requisitos de la formalidad procesal. La validez, o mejor dicho la 'firmeza' (soundness), en efecto, la 'obligatoriedad' o la 'fuerza' del precedente no es una cuestión de todo-o-nada ${ }^{55}$.

De este modo queda demostrado que las diferencias en el uso de la jurisprudencia entre los distintos países no resiste seguir siendo descrita por una teoría binaria de fuentes del Derecho. La teoría de fuentes del siglo XVIII tenía sus razones para ser tajante en distinguir entre lo que es y no es fuente formal. Pero esas razones históricas -el mensaje político en contra de los jueces enemigos de la revolución del siglo XVIII- ya no aplican en el siglo XXI. En consecuencia, ya no hay base para insistir en una versión estrictamente binaria de fuentes del Derecho. El derecho comparado nos ha demostrado que el uso de la jurisprudencia desborda su negación legal. Los países exhiben un mayor o menor grado de importancia del precedente en la interpretación. La teoría binaria debe ser reemplazada, de ahora en adelante, por una teoría gradual que dé cuenta de la interpretación de la jurisprudencia tal cual es hoy.

\section{REFORMAS A LA CORTE SUPREMA}

Los apartados anteriores se han enfocado a comprender, primero, el rol que juegan las decisiones judiciales previas en la interpretación dentro de la tradición jurídica del civil law y cómo el principal dogma de la teoría de fuentes del Derecho niega la jurisprudencia como un todo. Después al observar el derecho comparado notamos que las diferencias entre uno y otro país no son del todo-o-nada sino que admiten grados. En los siguientes apartados se aplicará todo ese marco teórico anterior sobre el caso chileno y la reforma del proceso civil que se propone.

Tradicionalmente la Corte Suprema en Chile ha conocido un recurso que se llama 'casación en el fondo' 56 pero que desde un punto de vista comparado en realidad no es Cassation francesa. La 'casación' chilena no solo anula y reenvía la sentencia -que sería el modelo genuinamente francés- sino que dicta una nueva sentencia de remplazo por sí ${ }^{17}$, acercándose más al modelo de Revision alemana ${ }^{58}$. Además la casación civil chilena, en proporción al tamaño del país, conoce muchos casos al año (más de 3000) ${ }^{59}$; en contraste con el certiorari de la U.S. Supreme Court, que termina conociendo y fallando no más de $100^{60}$.

El efecto secundario es una jurisprudencia abundante y caótica. Es relativamente fácil encontrar fallos a favor y en contra respecto a un mismo tipo de caso. Por eso tanto los litigantes como a los jueces inferiores (y a veces a los propios ministros de la Corte Su-

55 MacCormick y Summers (1997) p. 544.

56 CPC/1903 - Art. 764-808.

57 CPC/1903 - Art. 785.

58 Sobre los modelos de recursos ante la Corte Suprema, véase Geeroms (2002) pp. 201-212.

59 Más información sobre la casación chilena en MuÑoz (2010) pp. 90-182.

60 Wheeler (2004) p. 248. 
prema) tampoco se toman en serio la jurisprudencia de casación ${ }^{61}$. La facultad de recurrir al Pleno para unificar jurisprudencias si bien se contempla ${ }^{62}$, en la práctica no se utiliza ${ }^{63}$.

Desde la década de los noventa, entonces, Chile lleva a cabo un ciclo de reformas judiciales. Este movimiento se ha denominado 'Modernización de la Justicia'. Hasta el momento se han reformado ya distintas áreas, penal, familia, laboral, libre competencia, tributario. A futuro, es de esperar, se reformará también la justicia civil. Cada una de estas reformas ha afectado, de uno u otro modo, a la Corte Suprema.

Primero en 1995, además de crearse la Academia Judicial, se modificó el recurso de casación, la queja y el funcionamiento de las salas de la Corte Suprema. Esta reforma fue una reacción en contra de las malas prácticas que había desarrollado la Corte. Durante la década de los ochenta la Suprema desarrolló un criterio extremadamente formalista acerca de los requisitos de admisibilidad de la casación en el fondo. El resultado fue que se volvió un recurso al cual era muy difícil acceder. Como válvula de escape se terminó distorsionando el uso de la queja disciplinaria en contra de los jueces.

Para los litigantes tenía ventajas claras: la queja era menos formalista, más rápida y fácil de acceder. En vez de buscar la revocación de la sentencia con la casación, que era lo que correspondía, los litigantes buscaban el mismo objetivo utilizando la queja disciplinaria como excusa. Con el tiempo, la Suprema toleró y adhirió abiertamente esta práctica. La gran mayoría de los casos eran resueltos mediante queja y no en casación. Como la queja estaba escasamente regulada, la Suprema operaba como una tercera instancia sobre los hechos. Pero más grave aún, con la queja la Corte se permitía ser un verdadero tribunal de equidad, pasando por alto la legislación ${ }^{64}$.

Lo que hizo la reforma del 1995 fue, primero, regular la queja para restringir su uso. Y, segundo, relajar los requisitos de admisibilidad de la casación para reconducir nueva-

61 "[E]l principal escollo para un sustancial desarrollo de la jurisprudencia proviene, a nuestro entender, de una opción política que la Corte Suprema todavía no hace (o no quiere hacer) [...] nuestro máximo tribunal sigue formulando declaraciones que solo denotan la falta de voluntad para ejercer -de una vez por todas- el rol de órgano unificador de jurisprudencia’ Romero (2004) p. 96.

$62 \mathrm{CPC} / 1903$ - Art. 780. [En el civil law] the danger was always present that separate panels would deliver themselves of conflicting opinions on teh same point of law. To prevent this, various mechanism were developed to ensure internal consistency, one of which deviated from the above doctrine: if a panel of the court of last resort (often also a panle of a intermediate appellate court) wished to deviate from an opinion already anounced by any panel of the supreme court, the matter had to be certified so a superpanel for a decision binding on all judges of the supreme court.' DAMAšKa (1986) p. 37-38 nota al pie 39.

63 Romero (2004) p. 110.

64 Atria (2004) p. 267. Esta comprensión de hacer justicia material al parecer se mantiene como se desprende de las entrevistas a ministros de Cortes Suprema 'ahora en justicia penal es más necesario hacer una justicia material uno trata con seres humanos y cosas importantes como las privaciones de libertad y se piensa en ello, por lo mismo hay veces en que uno le dobla la mano a la ley cuando no se le ocurre otra cosa para lograr una sentencia más justa, uno le ve la cara a los relatores cuando uno le ha dicho blanco y luego le dice gris, contra incluso lo que yo he sostenido en mis libros yo renuncio por que el dolor de la pena lo merece y eso lo hice... aunque el ideal es que se tratare de uniformar para lograr una coherencia hacia el exterior, pero fíjese que dentro de la cárcel se agradece eso, porque la gente sabe que a una persona le aplicaron menos pena pero lo acepta por que a quién se favoreció es padre de familia, la gente entiende a veces la diferencia, que desde el punto de vista jurídico puro no debiera existir' Couso y Mera (2007) p. 352. Si esta autocomprensión se mantiene, se vuelve peligroso otorgar mayores facultades de fijar jurisprudencia. 
mente hacia ella el flujo de casos. Esta parte de la reforma tuvo éxito. La cantidad de recursos de queja disminuyó y la casación recuperó su protagonismo ${ }^{65}$.

La misma reforma además especializó a las Salas de la Corte Suprema. Antes las Salas de la Corte tenían competencias comunes. Esto, se pensaba, genera jurisprudencias de baja calidad porque la composición del tribunal que veía el caso era variable y los jueces se dedicaban a demasiadas áreas sin poder dominar alguna en concreto. La reforma, en consecuencia, estabilizó la composición de las Salas y les asignó materias específicas (Civil, Penal, Laboral y Administrativo-Constitucional). Esta otra parte de la reforma, en cambio, no tuvo el éxito que se esperaba. Los estudios de Couso \& Mera demostraron que -analizando la jurisprudencia de la Sala Penal del 1995 al 2002- el grado de uniformidad de la interpretación jurisprudencial no mejoró considerablemente con la especialización de las Salas ${ }^{66}$.

Después tuvo lugar la reforma del proceso penal. El procedimiento anterior concentraba la investigación y el juzgamiento en un mismo juez y por eso se criticó de inquisitivo. El nuevo proceso entrega la investigación a un Ministerio Público autónomo y el juzgamiento a un juez de garantía y a un tribunal oral colegiado en primera instancia.

El recurso ante la Corte Suprema también fue modificado. Antes, la Corte conocía un recurso de casación penal. Acorde con ese modelo, era un recurso relativamente fácil de acceder, con el que la Corte conocía muchos casos, por la causal amplia del error ('infracción') en la aplicación de la ley. La reforma redujo drásticamente el acceso a la Corte Suprema, limitándola a pocos casos en que se infringía un derecho fundamental o, aquí está lo importante, a solo aquellos casos en que existieran jurisprudencias contradictorias ${ }^{67}$.

La reforma al proceso laboral tuvo una evolución similar respecto de la Corte Suprema. Además de la oralización de los procedimientos de primera instancia, también se remplazó el recurso de casación laboral que conocía la Corte. El nuevo 'recurso extraordinario' limita el acceso y las competencias de la Corte a solo aquellos casos en que existieran jurisprudencias contradictorias en juego ${ }^{68}$.

La reforma en materia de justicia de familia optó por no alterar el sistema de recursos. Se oralizaron una vez más los procedimientos de primera instancia, mas contra la sentencia definitiva del juez cabe apelación y casación según las reglas generales del procedimiento civil ${ }^{69}$.

La reforma del proceso civil, por último, aún está en fase de discusión en el Congreso. El recurso ante la Corte Suprema es, de entre todos, el tema más sensible de la reforma. La casación ha acostumbrado a los abogados chilenos a que cotidianamente pueden plantear sus casos ante la Corte. Esto porque la casación garantiza un acceso amplio para presentar el recurso cada vez que, en opinión del perdedor, hay una errónea aplicación ('infracción') de la ley ${ }^{70}$.

65 Estas reformas de 1995 fueron diseñadas en el seno del Centro de Estudios Públicos CEP (1991) pp. 29 y ss.

66 Couso y Mera (2007) pp. 315-392.

$67 \mathrm{CPP} / 2000-$ Art. 376 inciso $3^{\circ}$.

68 CT/1994 - Art. $493+493-A$.

69 LF/2005 - Art. 61.

70 CPC/1903 - Art. 767. 
El proyecto de código procesal civil, tanto el del 2009 como el del 2012, proponen remplazar la casación chilena por un mismo tipo de recurso 'extraordinario' ${ }^{71}$. En ambos la participación de la Corte Suprema se reserva para cinco tipos de casos: (a) que existan jurisprudencias contradictorias; (b) el fallo actual ha contradicho una jurisprudencia anterior; (c) no existe jurisprudencia alguna sobre la materia; (d) que sea necesario cambiar la tendencia jurisprudencial ${ }^{72}$; y, por último (e) la infracción de derechos fundamentales en el fallo o en el procedimiento ${ }^{73}$. Este nuevo recurso extraordinario es reconocido explícitamente como 'el más importante cambio' en materia de recursos procesales.

Sin embargo entre los dos proyectos hay diferencias interesantes. El del 2009 incluía expresamente la discrecionalidad del certiorari -al modo de la US Supreme Court- para que la Corte seleccione los casos que conoce según si hay o no algún interés 'público' involucrado en su opinión ${ }^{74}$. El proyecto del 2012 prefiere hablar de un interés 'general', no señala expresamente que la selección sea discrecional, como en el del 2009, pero mantiene una redacción suficientemente amplia y flexible acerca de qué se entiende por ese interés general ${ }^{75}$.

Además, ambos proyectos tratan de un modo distinto los cambios en la tendencia jurisprudencial (overruling). El proyecto del 2009 señalaba expresamente que la Sala Civil de la Corte Suprema podía, por sí, cambiar la tendencia jurisprudencial si 'nuevos contextos históricos, sociales o culturales' lo justificaren ${ }^{76}$. Mientras que el proyecto del 2012, si bien permite asimismo el cambio de tendencia jurisprudencial, no señala la causal (la frase 'nuevos contextos históricos...' fue eliminada ${ }^{77}$. A cambio, el proyecto del 2012 somete los cambios de tendencia jurisprudencial no a la Sala Civil sino que al Pleno de la Corte Suprema ${ }^{78-79}$.

Entonces, descartando el caso de familia, podemos ver una tendencia en Chile. Se observa que tres de las cuatro materias de reforma procesal apuntan en direcciones similares respeto al recurso ante la Corte Suprema. Los movimientos de reforma, como vimos, han restringido ese acceso. La reforma penal, laboral y la que se proyecta en materias civiles tienden a remplazar la casación chilena por 'recursos de unificación' enfocados solo a los casos de jurisprudencia contradictoria ${ }^{80}$. Los errores en la aplicación de la ley, sin más, ya no tienen llegada a la Corte.

\footnotetext{
71 PCPC/2009 - Art. 353-362; PCPC/2012 Art. 405-416.

72 PCPC/2009 - Art. 354 (a) (b) (c) (d); PCPC/2012 Art. 409 (b).

73 PCPC/2009 - Art. 353 inciso 2o; PCPC/2012 Art. 409 (a).

74 PCPC/2009 - Art. 359. Para una visión crítica sobre introducir certiorari en Chile, véase Delgado (2012) pp. $361 \mathrm{y} \mathrm{ss.}$

75 PCPC/2012 - Art. 409.

76 PCPC/2009 - Art. 354 (d).

77 PCPC/2012 - Art. 409 (b).

78 PCPC/2012 - Art. 414 inciso $2^{\circ}$.

79 En la propuesta original del ministro Sergio Muñoz el overruling se regularía del siguiente modo 'La decisión adoptada en relación al recurso pendiente no afectará a los casos anteriores definitivamente resueltos. Por el contrario, dicha decisión tendrá efectos perentorios para los nuevos casos; sin embargo, la Corte Suprema podrá, transcurridos tres años y por razones fundadas, alterar la jurisprudencia' foja 62. Muñoz (2008) fojas 52 a 63.

80 CPP/2000 - Art. 376 inciso 3o; CT/1994 - Art. 483 + 493-A.
} 
Estos cambios procesales tienen varias repercusiones. La primera es el acceso. La casación anterior garantizaba un acceso relativamente amplio para que los litigantes pudieran presentar su caso ante la Corte. El nuevo tipo de recurso de unificación restringe ese acceso, volviendo difícil al litigante acceder a ella. La segunda es la cantidad de casos. Como la casación garantiza un acceso más amplio, la Corte termina conociendo una gran cantidad. Con los recursos de unificación, como el acceso es restringido, la Corte termina conociendo una cantidad reducida de casos.

El tercer efecto -que es el que nos interesa profundizar en este artículo- es que este cambio procesal puede alterar la práctica interpretativa de la Suprema. Con la casación la Corte se abocaba a revisar cómo se interpretó la ley. Con el nuevo tipo de recurso de unificación la Corte estará abocada a revisar cómo se interpretó la jurisprudencia.

Ahora bien, la Corte Suprema está ubicada en una posición clave. Tiene la última palabra en cada caso (res iudicata), sus fallos tienen un mayor peso relativo y ejerce un fuerte control disciplinario respecto del resto del Poder Judicial. Por eso los cambios a la Suprema tienen repercusiones en el resto del sistema jurídico. Si el nuevo régimen procesal cambia la práctica interpretativa de la Corte Suprema ¿cambiarán las prácticas interpretativas del resto de los operadores?

A partir de ahora la Corte entrará a conocer un caso solo si hay un conflicto de jurisprudencias que sea necesario zanjar. Un error en la aplicación o interpretación de la ley, sí solo, ya no permitirá acceder a ella. Además el fallo señalará explícitamente por cuál, de entre las tendencias jurisprudenciales en conflicto, tomará partido la Corte. La tendencia jurisprudencial ahí escogida será la que contará a futuro para evaluar si hay o no alguna contradicción entre jurisprudencias que permita acceder nuevamente la Corte para plantear un nuevo caso.

Por lo tanto ahora la jurisprudencia tendrá, al menos, un mayor valor estratégico para el litigante. Con la casación, para el que recurría era irrelevante tener o no jurisprudencia a su favor para poder acceder a la Corte. Con o sin ella lograría que su caso entre a ser conocido. Con los nuevos recursos de unificación, por el contrario, el litigante deberá tomarse en serio la jurisprudencia porque si no tiene alguna que citar a su favor, su caso podrá ser visto en primera o segunda instancia, pero no llegará a ser conocido por la Corte Suprema.

\section{5. ¿HACIA LOS PRECEDENTES?}

¿Esto significa que -esta es la pregunta central- con la reforma procesal civil la jurisprudencia empezará a ser fuente del Derecho en Chile de un modo similar al common law? Es una pregunta razonable porque, como vimos (supra II) la separación de poderes, teoría de fuentes -con la negación tajante de que la jurisprudencia no lo es-, codificación y casación son cuatro mecanismos de neutralización de los jueces que interactúan entre sí. Como en Chile la reforma del proceso civil está proponiendo remplazar la casación (el cuarto mecanismo) por un recurso de otra naturaleza; eso despierta una razonable preocupación sobre si se trastocará o no los otros mecanismos que interactúan, como el sistema de fuentes (el segundo). 
El debate está entrampado en este punto. Por una parte, las reformas procesales (penal, laboral y a futuro civil) están aumentando la importancia de la jurisprudencia. Por la otra, el artículo tres del código civil ha establecido tradicionalmente que la jurisprudencia no es fuente del Derecho en Chile. Estas reformas procesales, entonces, parecieran estar volviendo subrepticiamente a la jurisprudencia fuente del Derecho al aumentar su importancia.

Sin embargo el artículo tres no está siendo explícitamente derogado por las reformas procesales, continúa el debate, y existirían buenas razones para no hacerlo ${ }^{81}$. El dogma de que la jurisprudencia no es fuente formal es una parte constitutiva de nuestra tradición jurídica que deberíamos conservar ${ }^{82}$. Eso nos enfrentaría a un dilema en que las únicas soluciones al debate serían que o las reformas procesales deberían echar pie atrás o renunciamos a nuestra tradición de fuentes.

En mi opinión el debate está entrampado porque se sigue abordando sobre una teoría binaria de fuentes del Derecho. La teoría binaria no es capaz de comprender que la jurisprudencia pueda aumentar su importancia sino solo mediante algún cambio en su reconocimiento como fuente formal. Y si la jurisprudencia de hecho aumenta su importancia, sea por una vía procesal u otra, sin cambiar explícitamente ese reconocimiento formal, entonces necesariamente se violentaría la teoría binaria.

Es cierto, con los nuevos recursos de unificación la jurisprudencia aumentará su valor. Pero para dar cuenta de ese fenómeno interpretativo necesitamos una teoría que sí admita grados. Si se remplaza la teoría binaria por una gradual el dilema desaparece. Con una teoría gradual de fuentes sí se vuelve posible que, sin pasar por un reconocimiento formal como fuente, la jurisprudencia pueda aumentar su importancia con las reformas procesales.

Recordemos la escala gradual que nos propone MacCormick \& Summers. El rol que tiene el precedente en la interpretación admite cuatro grados. En el grado más alto (1\%) está la 'vinculación formal' (que es lo que entendemos por que la jurisprudencia sea 'fuente formal del Derecho'). En los siguientes tres grados la jurisprudencia tiene mayor o menor importancia en la interpretación pero en ninguna es formalmente fuente. En el segundo grado los fallos anteriores 'tienen fuerza' (2o); en el tercer grado sirven de 'apoyo adicional' ( $\left.3^{\circ}\right)$; y en el cuarto tienen un mero 'valor ilustrativo' (4\%).

\footnotetext{
81 'Una sexta y última objeción se refiere a que la unificación de jurisprudencia se opone al sistema de fuentes de la familia jurídica europeo-continental. Al respecto, parece posible afirmar que, empíricamente hablando, en dicho entorno jurídico cultural se rechaza otorgar a la jurisprudencia el carácter de fuente del Derecho. La adopción de esta perspectiva puede tener justificaciones ideológicas o simplemente culturales. Así, y desde un plano ideológico, admitir que las decisiones judiciales tienen fuerza normativa provocaría la confusión de funciones del Estado y, según sostiene algún autor, incluso conllevaría la destrucción del estado de Derecho. Desde una perspectiva cultural, muchos juristas se niegan a abandonar la concepción tradicional del juez como mero aplicador del Derecho. En cualquiera de los dos casos se trata de una consciente oposición a la unificación de jurisprudencia pretendida por el recurso extraordinario.' Delgado y Díaz (2011) pp. 297-296.

82 'Nos merece particularmente este reproche: Especialmente, el tratamiento del recurso extraordinario y la derogación de la casación civil, institución que viene a garantizar en última instancia el principio constitucional de igualdad en la aplicación de la ley a todos los ciudadanos, sin olvidar el hecho de que altera el sistema de fuentes del derecho en nuestro sistema jurídico. Todo ello, sin quedar claridad respecto del papel que tendrá la Corte Suprema con el recurso extraordinario, y los graves conflictos que se podrán producir en el marco de dicho recurso, con las facultades del Tribunal Constitucional', AA.VV. (2012) p. 1.
} 
Aclarado esto nos podemos formular nuevamente la pregunta central de este artículo: ¿Con la reforma procesal civil la jurisprudencia pasará a ser fuente del Derecho en Chile? La respuesta es 'no'. Pero no porque la jurisprudencia no vaya a aumentar su valor con los nuevos recursos de unificación (que sí aumentará); sino porque -y esta es la tesis que planteo para contestarla- queda en entredicho que la versión 'binaria' de la teoría de fuentes del siglo XVIII siga vigente para Chile del siglo XXI.

Si la remplazamos por una teoría gradual, notamos que en la situación actual -antes de la reforma procesal civil- la jurisprudencia no es fuente del Derecho porque carece de vinculación formal $\left(1^{\circ}\right)$. Como vimos, supra II, el artículo tres del código civil niega su reconocimiento como fuente. En Chile hoy la jurisprudencia -según la escala de MacCormick \& Summers- tiene un valor en algún punto entre $\left(3^{\circ}\right)$ y $\left(4^{\circ}\right)$. Actualmente sirve de apoyo adicional o se usa con un mero valor ilustrativo, pero no tiene ninguna fuerza especial $\left(2^{\circ}\right)$.

Si utilizamos la misma teoría gradual para predecir el escenario futuro -después de la reforma procesal civil- notaremos que la jurisprudencia tampoco pasará a ser fuente del Derecho. Con los cambios a los recursos ante la Corte Suprema -el remplazo de la casación por recursos de unificación- la importancia de la jurisprudencia aumentará en Chile. Pero si aplicamos la escala de MacCormick \& Summers para observar la reforma notaremos que no se busca alcanzar el grado $\left(1^{\circ}\right)$ de vinculación formal (lo que sí sería propiamente 'fuente del Derecho' y requeriría reforma del artículo tres del código civil). Para demostrarlo veamos los siguientes tres puntos.

El primero es observar hacia el delito de prevaricación. Si la jurisprudencia pasara al estatus de fuente formal del Derecho, entonces debería cambiar la tipificación de la prevaricación ${ }^{83}$. Si la jurisprudencia es genuinamente Derecho, entonces el juez que a sabiendas fallara contra un precedente -y no solo contra 'ley expresa' como dice la tipificación actualcometería también prevaricación. Pero ese no es el caso. La reforma procesal civil no propone ampliar la tipificación de la prevaricación.

El segundo punto es observar los requisitos de fundamentación. Si la jurisprudencia pasara a ser fuente formal, entonces la jurisprudencia debería estar explícitamente señalada en los requisitos de la sentencia definitiva, en aquella parte que prescribe cómo el juez debe fundamentar el Derecho que aplica al caso. Pero ese no es el caso. El artículo 206 del PCPC/2012 menciona a la ley, la constitución, los tratados internacionales e incluso a los principios jurídicos, pero omite a la jurisprudencia ${ }^{84}$.

$83 \mathrm{CP} / 1874$ - Art. 223: 'Los miembros de los tribunales de justicia colegiados o unipersonales y los fiscales judiciales, sufrirán las penas de inhabilitación absoluta perpetua para cargos y oficios públicos, derechos politicos y profesiones titulares y la de presidio o reclusión menores en cualesquiera de sus grados:- $1^{\circ}$ Cuando a sabiendas fallaren contra ley expresa y vigente en causa criminal o civil.'

84 PCPC/2012 - Art. 206: Requisitos de la sentencia definitiva. Las sentencias definitivas que ponen término al primer grado jurisdiccional se dictarán siempre por escrito y deberán contener: 5. Los preceptos constitucionales, legales y los contenidos en tratados internacionales vigentes, $y$, en su defecto, los principios generales de derecho y de equidad con arreglo a los cuales se pronuncia la sentencia, y el razonamiento jurídico que justifica su aplicación. 
El tercer y último punto para demostrar que la reforma no busca volver a la jurisprudencia fuente formal es comparar la propuesta del 2008 del ministro de la Corte Suprema Sergio Muñoz ${ }^{85}$, por una parte, con el proyecto de código del 2012.

Propuesta Muñoz - 2008: "Art. \#\#. La decisión que se adopte en cuanto a la cuestión jurídica planteada será obligatoria para todos los Ministros y Salas de la Corte Suprema $[\ldots] "$.

Proyecto de CPC-2012: "Art. 413. Fallo del Recurso. En la sentencia la Corte Suprema deberá exponer [...] la manera en la cual deberá ser interpretada o aplicada una determinada norma o principio jurídico [...]”.

Si bien las redacciones son distintas, parecieran referir a lo mismo. Ambas hablan sobre la resolución de la Corte ('La decisión'-'En la sentencia'); ambas refieren a la interpretación del Derecho ('cuestión jurídica'-interpretada o aplicada una determinada norma o principio jurídico') y ambas utilizan una expresión imperativa respecto de ella ('será obligatoria'-'deberá ser'). Esos tres elementos comunes harían concluir, en una lectura apresurada, que las dos redacciones denotan hacia lo mismo. Pero no. Si ponemos atención notaremos que entre ambas redacciones hay una diferencia fundamental: la primera contradice el artículo tres del código civil, la segunda no; la primera dice que la jurisprudencia será fuente del Derecho y la segunda no lo dice.

La razón es que, en rigor, uno y otro regulan cuestiones distintas. Mientras la propuesta Muñoz regula los efectos de la sentencia de la Suprema ('será', tendrá el efecto de ser 'obligatoria para los...'); el proyecto del 2012 regula el contenido de esa sentencia ('la sentencia de la Corte Suprema deberá exponer'). La diferencia es importante porque de los deberes de contenido de la sentencia no se derivan los efectos de la sentencia con ese contenido. Sería excesivo concluir que, porque la Suprema tiene el deber de señalar en su sentencia cuál es -en su opinión- la interpretación que debería seguirse, que esa interpretación ahí señalada deberá seguirse. De que la sentencia deba contener la postura de la Corte respecto de cuál interpretación debería prevalecer, no se deriva el efecto de que esa postura de la Corte sea obligatoria para los demás. El artículo 473 del proyecto es un deber para la Suprema de posicionarse, de tomar partido explícitamente, en el debate interpretativo; pero no es un deber para los demás tribunales de cuadrarse con esa posición (como sí lo es la propuesta Muñoz).

En consecuencia, para que la jurisprudencia sí pasara a ser fuente formal del Derecho con el proyecto de código procesal -además del artículo que ya está con el deber para la Corte de posicionarse en el contenido de su fallo- sería necesario otro artículo que le atribuyera efectos obligatorios a ese fallo. Pero ese no es el caso. El proyecto no tiene un símil a la propuesta Muñoz que regule los efectos del fallo de la Suprema. Y sin una regla especial sobre efectos de la sentencia en el nuevo código procesal, entonces sigue rigiendo la regla general del código civil sobre efectos de las sentencias: las sentencias judiciales segui-

85 'La decisión que se adopte en cuanto a la cuestión jurídica planteada será obligatoria para todos los Ministros y Salas de la Corte Suprema’ MuÑoz (2008) foja 62. 
rán sin tener fuerza obligatoria sino respecto de las causas en que actualmente se pronunciaren.

Estos tres puntos sirven para demostrar que la reforma no busca llegar al grado más alto de la vinculación formal. La reforma busca, en cambio, subir la importancia de la jurisprudencia a un punto intermedio entre los grados $\left(2^{\circ}\right)$ y $\left(3^{\circ}\right)$. La jurisprudencia dejará de ser un dato meramente ilustrativo $\left(4^{\circ}\right)$ porque ahora las contradicciones entre fallos anteriores tienen un efecto práctico, permitir o no el acceso del litigante a la Corte Suprema.

Mas que la sentencia del tribunal inferior contradiga un precedente no significa que el fallo deberá necesariamente ser revocado -que sería lo propio del grado $\left(1^{\circ}\right)$ - sino que hay una posibilidad no necesaria de que sea revocado, que es lo propio del grado $\left(2^{\circ}\right)$. El artículo 409 (b) del PCPC/2012, recordemos, establece criterios de admisibilidad pero no criterios para el fallo en el fondo. Es decir, el 409 (b) establece criterios para que la Suprema decida si entrar o no entrar a conocer un caso; pero no establece los criterios conforme a los cuales deberá decidirlo, si accedió a entrar a conocerlo. Por lo tanto, que el fallo contradiga un precedente contará como una buena razón para que la Corte entre a conocer el caso; pero la Corte puede finalmente decidir confirmar o revocar ese fallo por consideraciones de otro orden.

La jurisprudencia deja de ser un dato meramente ilustrativo $\left(4^{\circ}\right)$ también porque si un fallo se aparta de ella, si bien no lo vuelve contrario a Derecho, la hace objeto de críticas, que es lo propio de $\left(2^{\circ}\right)$. Un juez inferior que se aparta de la jurisprudencia que explícitamente unificó la Suprema ya no puede esgrimir una libertad de conciencia. Deberá dar razones de por qué decidió de otro modo sabiendo de antemano que, por el hecho de apartarse en sí, sus razones podrían llegar a ser revisadas por la misma Corte Suprema que unificó.

Además, se incrementa el rol de apoyo a las decisiones ( $3^{\circ}$ ). Un fallo que cita explícitamente la jurisprudencia anterior con la que ella es consistente adquiere un peso adicional. Que la sentencia sí esté conforme con la jurisprudencia anterior cierra la posibilidad de que entre a ser revisada por la Corte Suprema. En suma, con la reforma la jurisprudencia dejará de ser un dato meramente ilustrativo $\left(4^{\circ}\right)$ y pasará a tener alguna fuerza propia $\left(2^{\circ}\right)$ o al menos aumentará su valor como apoyo adicional a la decisión débil $\left(3^{\circ}\right)$. Con la reforma procesal civil la jurisprudencia no se volverá fuente del Derecho porque la reforma busca aumentar su importancia en grados menores a la vinculación formal.

Con una teoría binaria, entonces, queda finalmente desanudado el dilema. Solo si la reforma pretendiera llegar al nivel $\left(1^{\circ}\right)$ de vinculación formal, recién ahí sería necesario reformar el artículo tres del código civil, que es el que niega ese reconocimiento de la jurisprudencia como fuente. Pero ese no es el caso. La reforma busca aumentar la importancia solo a $\left(2^{\circ}\right)$ y $\left(3^{\circ}\right)$ y para esos dos grados -tener fuerza o servir de apoyo adicional- no se requiere su reconocimiento formal. Luego, para que la reforma procesal civil logre aumentar solo hasta ahí la importancia de la jurisprudencia, que es lo que se propone, no requiere reformar el artículo tres del código civil. De este modo se puede lograr las dos cosas que el dilema volvía disyuntivas: bajo una teoría gradual sí es posible llevar adelante las reformas procesales, aumentando la importancia de la jurisprudencia, y hacerlo sin estar renunciando a nuestra tradición que niega su reconocimiento como fuente formal. 
Es tiempo de abandonar en Chile la teoría binaria de fuentes heredada de la revolución. Los jueces del siglo XXI ya no son los enemigos del siglo XVIII, en consecuencia ya no necesitamos un mensaje político tajantemente prohibitivo contra ellos. Como concluyen MacCormick \& Summers al final de su estudio, estamos forzados a repensar la noción todo-o-nada de las 'fuentes del Derecho'. El consejo que nos dan es 'esquivar' la aproximación del civil law que, por sus paradigmas dominantes, se niega a calificar el precedente como 'fuente formal's6.

\section{CONCLUSIÓN}

Este artículo trató acerca de un tema de interpretación jurídica. En concreto, se estudió cómo la reforma procesal civil podría afectar el rol de la jurisprudencia en la interpretación. La pregunta que se planteó contestar es si acaso la reforma vuelve a la jurisprudencia fuente del Derecho en Chile. Para abordar esta pregunta el artículo se dividió en cuatro apartados.

En el primero se enfocó sobre tradición jurídica del civil law y a comprender cuál es el origen, contexto y función de la teoría de fuentes dentro de esa tradición. Se concluyó que la teoría de fuentes -junto con la separación de poderes como aislación, la codificación y la gran casación- son mecanismos que interactúan entre sí para controlar a los jueces. El propósito por el cual se desarrollaron estos mecanismos fue para que los revolucionarios franceses pudieran neutralizar a los jueces aristócratas partidarios de conservar el ancien regime. La teoría de fuentes del Derecho cumple la función de aislar, jerarquizar y excluir a priori los criterios de decisión judicial. Ahora bien, por el contexto histórico en el cual surgió, la teoría de fuentes debió ser formulada binariamente. La teoría de fuentes excluye tajantemente a la jurisprudencia -ese es su dogma más importante- porque tras ellas hay un mensaje político en contra de los jueces enemigos, para no dejar espacios de discrecionalidad para la oposición a la revolución. Chile pertenece a la tradición jurídica del civil law y, en consecuencia, le asigna importancia a los cuatro mecanismos de neutralización de los jueces. El código civil chileno consagra la teoría de fuentes y también formula su dogma más importante. El artículo tercero y el 1437 niega a la jurisprudencia como fuente.

El segundo apartado se enfoca en el derecho comparado. Notamos ahí que en Inglaterra la judicatura jugaba un rol totalmente distinto. Los jueces eran aliados de la revolu-

\footnotetext{
86 'Finally, we are forced to rethink a further concept which recurs throughout this book, and in much legal thought, namely that of a 'source of law'. We have variously stated and implied that it is an important difference between legal systems whether precedent is a formal source of law' or not. In terms of the self-characterization of legal systems, achieved under de dominant paradigms of legal thought, this is quite accurate and unobjectionable. Common law systems do differ from the systems of codified law in what they characterize as their own formal sources'. However, once we draw clear attention to the difference between procedurally formal norm-creating acts, which do admit of all-ornothing validity, and discursive or deliberative procedures of elaborating legal justifying grounds for decisions and the like, and once we ascribe legal normative force to a greater or lesser degree to the importantly varying products of this process, we see that there is a hopeless ambiguity in applying the term 'source' to both these cases. At that rate, we should 'side' with the civilian approach that refuses to classify precedent as a 'formal source'; but we should also 'side' with the common law in holding that nevertheless the propositions that are elaborated in this process have a genuinely legal quality, though having more or less soundness, greater or less weight.' MaCCormick y Summers (1997) p. 545.
} 
ción y en consecuencia no era necesario desarrollar mecanismos de neutralización en contra de ellos. La separación de poderes fue entendida como pesos-y-contrapesos, la codificación es marginal, las Cortes Supremas no ejercen propiamente una casación. En el common law no se dio una teoría de fuentes binaria y tajante. Y el dogma corolario que niega la jurisprudencia no solo no se dio allá sino que los precedentes son valiosamente reconocidos. Del mismo modo, desde el common law la diferencia con el civil law no se ve binariamente. En ambas tradiciones se consideran las decisiones anteriores pero en distinto grado. El civil law 'no tiene precedentes' porque no reconoce que un caso individual pueda cambiar tendencias de decisión judicial. En cambio, desde la perspectiva del common law, el civil law tiene un sistema de 'jurisprudencia constante' en donde se reconocen los criterios judiciales solo si están reiterados en una serie innumerable de fallos anteriores.

Entonces el rol de la jurisprudencia en la interpretación, al observar el Derecho comparado, no se presenta como un todo-o-nada sino como una variedad de grados. Para dar cuenta de esa variedad este artículo introduce la teoría gradual de MacCormick \& Summers. Bajo la escala que proponen ellos hay cuatro grados. En el más alto la jurisprudencia tiene 'vinculación formal' $\left(1^{\circ}\right)$, después la jurisprudencia puede 'tener fuerza' $\left(2^{\circ}\right)$, si no, ella puede servir de 'apoyo adicional' a una decisión débil $\left(3^{\circ}\right)$ y, por último, puede servir al menos de dato ilustrativo $\left(4^{\circ}\right)$. Las conclusiones de MacCormick \& Summers al observar el derecho comparado son que, primero, el common law está en el grado más alto $\left(1^{\circ}\right)$. Sin embargo ahí aún la vinculación formal admite excepciones, derrotabilidad o modificación (overruling). En el civil law, en cambio, la jurisprudencia tiene más importancia de lo que se está dispuesto a admitir. Si bien no tiene vinculación formal (10), en el civil law los fallos tienen una fuerza importante $\left(2^{\circ}\right)$ y sirven de un apoyo adicional $\left(3^{\circ}\right)$. En Chile actualmente, bajo la misma escala, la jurisprudencia tampoco tiene vinculación formal. Pero estaría en un punto más bajo de la escala, entre $\left(3^{\circ}\right)$ que sirve de apoyo adicional o son datos meramente ilustrativos $\left(4^{\circ}\right)$.

Ahora bien -se abordó en el tercer y cuarto apartado- la reforma procesal civil, junto a las anteriores reformas procesales, que proponen reformas a la Corte Suprema. La tradicional casación de ley está siendo remplazada por recursos de unificación. Estas reformas despiertan la crítica severa que, a propósito de una reforma procesal, se estaría subrepticiamente volviendo a la jurisprudencia fuente del Derecho en Chile, trastrocando un elemento central de la tradición del civil law. En este artículo se responde esa crítica. Si se reemplaza la teoría binaria de fuentes por una gradual de MacCormick \& Summers se puede observar que la reforma procesal civil puede aumentar la importancia de la jurisprudencia sin requerir un reconocimiento formal que pase a llevar el artículo tres del código civil. Al observar la tipificación de la prevaricación, los requisitos de fundamentación de la sentencia definitiva y la propuesta del ministro Sergio Muñoz concluimos que la reforma busca aumentar la importancia de la jurisprudencia a un punto intermedio entre $\left(2^{\circ}\right)$ y $\left(3^{\circ}\right)$, pero no hasta el $\left(1^{\circ}\right)$ de vinculación formal. Con esta visión se puede sortear el dilema, se puede llevar adelante la reforma procesal sin renunciar a nuestra tradición de fuentes. 


\section{BIBLIOGRAFÍA CITADA}

AA.VV. (2012): "Comentarios al proyecto de ley que establece el Código Procesal Civil" Disponible en: <http://www.reformasprocesales.udp.cl/wp-content/uploads/2010/09/ cartaprofesoresdecivil.pdf $>$.

AA.VV. (2012): "Declaración sobre Reforma Procesal Civil, X jornadas nacionales de Derecho Civil" Disponible en: <http://www.larazondelderecho.com/?cat=opinion\&id=42>.

Alexy, Robert (2007): Una teoría de la argumentación jurídica (trad. Manuel Atienza e Isabel Espejo, Madrid, Centro de Estudios Políticos y Constitucionales, segunda edición) 374 pp.

Atria, Fernando (2004): "Proceso civil ('la casación como problema')", Revista de Derecho de la Universidad Adolfo Ibáñez, vol. II: pp. 249-353.

Bankowski, Zenon (1997): MacCormick, Neil y Marshall, Geoffrey (1997): "Precedent in the United Kingdom", en MacCormick, Neil y Summers, Robert (edits.), Interpreting precedents: A comparative study (Aldershot, Dartmouth Publishing) pp. 315-354.

Cappalli, Richard B. (1992): "Procedimiento civil comparado: Estados Unidos, Chile y Sudamérica”, Revista Chilena de Derecho, vol. IXX No 2: pp. 203-275.

Centro de Estudios Públicos (1991): Propuestas para la Reforma Judicial (Santiago, Centro de Estudios Públicos) 395 pp.

Chase, Oscar y Walker, Janet Elizabeth (2010): Common Law, Civil Law and the future of categories (Ontario, LexisNexis) 666 pp.

Couso, Jaime (2007): "El rol uniformador de la jurisprudencia en la sala penal de la corte suprema: Anatomía de un fracaso", Revista de Derecho de Valdivia, vol. XX: pp. 147-172.

Couso, Jaime y Mera, Jorge (2007): "El rol uniformador de la jurisprudencia de la sala penal de la Corte Suprema. Estudio empírico”, Revista Ius et Praxis, vol. XIII Nº1: pp. 315-392.

DamašKa, Mirjan (1986): The faces of justices and State Authority. A comparative approach to the legal process (London, Yale Univesity Press) $247 \mathrm{pp}$.

Dawson, John (1987): The oracles of the law (New York, University of Michigan) pp. 520.

Delgado, Jordi (2012): "El certiorari: un agente extraño en manos de nuestra Corte Suprema” Revista Actualidad Jurídica, vol. XXII: pp. 361-387.

Delgado, Jordi y Díaz, Iván (2011): "La unificación de jurisprudencia pretendida por el recurso extraordinario: ventajas y problemas", Revista de Derecho Universidad Católica del Norte - Sede Coquimbo, vol. XVIII: pp. 275-304.

Geeroms, S. M. F. (2002): "Comparative Law and Legal Translation: Why the Terms Cassation, Revision and Appeal Should Not Be Translated”, American Journal of Comparative Law, vol. L: pp. 201-212.

GÉNY, Françoise (1925): Métodos de interpretación y fuentes en derecho privado positivo (Madrid, Reus) 695 pp.

Glendon, Mary; Carozza, Paolo y Picker, Colin (2008): Comparative legal traditions ${ }^{3}$ (St. Paul, West Publishing) 366 pp.

Lasser, Mitchel (2004): Judicial Deliberations: A Comparative Analysis of Transparency and Legitimacy (New York, Oxford University Press) 396 pp. 
Le Sueur, Andrew (edit.) (2004): Building the UK's New Supreme Court: National and Comparative Perspectives (New York, Oxford University Press) 376 pp.

MacCormick, Neil y Summers, Robert (edits.) (1997): Interpreting precedents: A comparative study (Aldershot, Dartmouth Publishing) 585 pp.

MacCormick, Neil y Summers, Robert (1997): "Further general reflections and conclusions", en MacCormick, Neil y Summers, Robert (edits.), Interpreting precedents: A comparative study (Aldershot, Dartmouth Publishing) pp. 531-550.

Marinoni, Luiz Guilherme (2010): Precedentes obrigatórios (São Paulo, Revista dos Tribunais) $542 \mathrm{pp}$.

Merryman, John Henry y Pérez-Perdomo, Rogelio (2007): The civil law tradition. An introduction to the legal systems in Europe and Latin America ${ }^{3}$ (Standford, Standford University Press, tercera edición) 192 pp.

MuÑoz, Sergio, Unificación de Jurisprudencia (Asunto Administrativo), Rol AD-168-2008, foja 52 a 63 [3 de julio del 2008, Corte Suprema].

Muñoz, Sergio (2010): "Presente y futuro de la casación civil”, en TAvolari, Raúl (edit.), Derecho procesal contemporáneo. Ponencias de las XXII Jornadas Iberoamericanas de Derecho Procesal, Tomo I (Santiago de Chile, Punto Lex-Thomson Reuters) pp. 90-182.

Paillás, Enrique (2008): El recurso de casación: derecho chileno y comparado (Santiago, Editorial Jurídica de Chile) $184 \mathrm{pp}$.

Romero, Alejandro (2004): La jurisprudencia de los tribunales como fuente del derecho. Una perspectiva procesal (Santiago, Editorial Jurídica de Chile) 149 pp.

TAPIA, Mauricio (2005): Código Civil 1855-2005 Evolución y Perspectivas (Santiago, Editorial Jurídica de Chile) $471 \mathrm{pp}$.

Tavolari, Raúl (edit.) (2010): Derecho procesal contemporáneo. Ponencias de las XXII Jornadas Iberoamericanas de Derecho Procesal, Tomo II (Santiago de Chile, Punto LexThomson Reuters) 1438 pp.

Troper, Michel y Grzegorczyk, Christophe (1997), Precedent in France, en MacCormick, Neil y Summers, Robert (edits.), Interpreting precedents: A comparative study (Aldershot, Dartmouth Publishing) pp. 103-140.

Wheeler, Russell (2004): "Intermediate Courts of Appeals and Their Relations with Toplevel Courts: the US Federal Judicial Experience”, en Le Sueur, Andrew (edit.), Building the UK's New Supreme Court: National and Comparative Perspectives (New York, Oxford University Press) pp. 237-270.

Whittaker, Simón (2008): "El precedente en el derecho inglés. Una visión desde la ciudadela”, Revista Chilena de Derecho, vol. XXXV N 1: pp. 37-83.

Zweigert, Konrad y KöTz, Hein (1998): An introduction to comparative law (Oxford, Clarendon Press, tercera edición) 714 pp.

\section{NORMAS CITADAS}

Constitución Política de la República de 1980. (art. 73).

Código Civil de 1856. (art. 1, 2, 3, 7, 14, 407, 553, 697, 1437, 1622, 2226 y 2489).

Código de Procedimiento Civil de 1903. (art. 764 a 808). 
Bravo-Hurtado, Pablo — "Hacia los precedentes en Chile: Reforma Procesal Civil y Fuentes del Derecho"

Código Penal de 1874. (art. 223).

Código Procesal Penal de 2000. (art. 376).

Código del Trabajo de 1994.( art. 493, 483).

Ley No 19.968 del 1 de octubre de 2005, que crea los Tribunales de Familia. (art. 61).

Proyecto de Ley que Aprueba un Nuevo Código Procesal Civil de 2009. (art. 353 a 362).

Proyecto de Ley que Establece un Nuevo Código Procesal Civil de 2012. (art. 206, 406 a 416 y art. 473).

\section{ABREVIATURAS UTILIZADAS}

ACPC/2006 = Anteproyecto de Código Procesal Civil. Universidad de Chile.

CC/1856 = Código Civil.

$\mathrm{CP} / 1874$ = Código Penal

CPC/1903 = Código de Procedimiento Civil.

CPP $/ 2000$ = Código Procesal Penal.

CT/1994 = Código del Trabajo.

PCPC/2009 = Proyecto de Ley que Aprueba un Nuevo Código Procesal Civil.

PCPC/2012 = Proyecto de Ley que Establece un Nuevo Código Procesal Civil.

TF/2005 = Ley que Crea los Tribunales de Familia. 